\title{
Genetic conversion of proliferative astroglia into neurons after cerebral ischemia: a new therapeutic tool for the aged brain?
}

\author{
Aurel Popa-Wagner • Dirk Hermann • Andrei Gresita
}

Received: 21 May 2019 / Accepted: 2 July 2019 / Published online: 12 July 2019

(C) American Aging Association 2019

\begin{abstract}
Ischemic stroke represents the 2nd leading cause of death worldwide and the leading cause for long-term disabilities, for which no cure exists. After stroke, neurons are frequently lost in the infarct core. On the other hand, other cells such as astrocytes become reactive and proliferative, disrupting the neurovascular unit in the lesioned area, especially in the aged brain. Therefore, restoring the balance between neurons and nonneuronal cells within the perilesional area is crucial for post stroke recovery. In addition, the aged post stroke brain mounts a fulminant proliferative astroglial response leading to the buildup of gliotic scars that prevent neural regeneration. Therefore, "melting" glial scars has been attempted for decades, albeit with little success. Alternative strategies include transforming inhibitory gliotic tissue into an environment conducive to neuronal regeneration and axonal growth by genetic conversion of astrocytes into neurons. The latter idea has gained momentum following the discovery that in vivo direct lineage reprogramming in the adult mammalian brain is a feasible strategy for reprogramming nonneuronal cells into neurons. This exciting new
\end{abstract}

Andrei Gresita contributed equally to this work.

A. Popa-Wagner · A. Gresita

Center of Clinical and Experimental Medicine, University of

Medicine and Pharmacy, Craiova, Romania

A. Popa-Wagner $(\triangle) \cdot$ D. Hermann

Vascular Neurology, Dementia and Ageing Research, Department of Neurology, University of Duisburg-Essen, University Hospital Essen, 45122 Essen, Germany

e-mail: aurel.popa-wagner@geriatrics-healthyageing.com technology emerged as a new approach to circumvent cell transplantation for stroke therapy. However, the potential of this new methodology has not been yet tested to improve restoration of structure and function in the hostile environment caused by the fulminant inflammatory reaction in the brains of aged animals.

Keywords Aging $\cdot$ Cerebral ischemia $\cdot$ Therapy $\cdot$ Glial scar. Genetic conversion

\section{Aging and cerebral ischemia}

Cerebrovascular infarct represents one of the leading causes of death and sustained disability worldwide. The debilitating neurological impairments of stroke survivors are also associated with huge socioeconomic losses which further aggravate the consequences of this disease.

Age is the principal nonmodifiable risk factor for stroke. The incidence of stroke increases significantly with age in both men and women, with half of all strokes occurring in people over 75 years and one third in people over 85 years (Roger et al. 2012). In addition, there is an age-dependent increase in conversion of ischemic tissue into infarction that suggests that age is a biological marker for the variability in tissue outcome in acute human stroke (Ay et al. 2005).

Neuroprotection studies in young animals have demonstrated the efficacy of a variety of pharmacological interventions. Yet, all strategies that have clinically been tested in larger trials failed to show benefits in aged humans. One possible explanation for this discrepancy 
between experimental and clinical studies may be the role that age plays in the recovery of the brain from stroke insults (Popa-Wagner et al. 2014; Hermann et al. 2019). In this light, the aged postacute animal model is clinically most relevant to stroke rehabilitation, as recommended by the Stroke Progress Review Group (STAIR 1999).

\section{Therapy of cerebral ischemia}

Treatments for stroke patients are still very limited. Invasive treatment methods such as thrombolysis and intraarterial trombectomy must be used within a few hours of stroke onset and cannot be used during the recovery phase. Craniotomy which is also an invasive procedure involves huge risks and is only used for large strokes.

When it comes to clinical practice, post stroke brain recovery is mostly stimulated using physical therapy. The mechanism behind this method of therapy probably consists in the recruitment of perilesional neuronal circuits. However, physical therapy cannot provide replacement for the lost tissue as a result of the ischemic injury.

It is well known that the aged brain has a limited inherent capacity for repair. Neurons are postmitotic cells which do not possess the ability to regenerate once lost due to spinal or cerebral traumatic injuries or neurodegeneration. However, two brain regions maintain their capacity of neurogenesis, the subventricular zone (SVZ) of the lateral ventricle and the subgranular zone (SGZ) of the dentate gyrus (Kriegstein and AlvarezBuylla 2009; Ming and Song 2011; Kempermann et al. 2015). It is important to mention that some studies suggest that neurogenesis can also occur in nonneurogenic brain regions after stroke (Arvidsson et al. 2002; Darsalia et al. 2005; Jin et al. 2006; Nadareishvili and Hallenbeck 2003).

Therefore, new therapeutic methods for stroke use a different approach by targeting the so-called stroke-induced neurogenesis (Arvidsson et al. 2002; Darsalia et al. 2005). However, the sole presence of new neurons is not enough. A well-orchestrated sequence of steps is needed in order to ensure the timely generation of new cells, their migration to the sites of injury, and their differentiation and integration into the preexisting circuitry (Hou et al. 2008; Wang et al. 2009; Sun et al. 2012; Zhang et al. 2013).

The constant search for new, improved therapies in the field of neurobiology has also unveiled the potential of cell-based therapies. This approach is aimed at replacing neurons that are lost after stroke by using cellular transplantation and has become an attractive therapeutic alternative for brain injuries and neurodegeneration with the aim to stimulate the restorative processes in the ischemic brain.

A number of different cell types, such as induced pluripotent stem cells (iPSCs) and iPSC-derived neural stem cells (NSCs) or neurons, have been tested, taking into consideration their abilities to improve neural function after injury. Indeed, induced pluripotent stem cells (iPSCs) improve behavior and form neurons after implantation into the stroke-injured adult rodent brain (Okano and Yamanaka 2014).

However, how the aged brain responds to grafted iPSCs is not well documented. In previous work, we have shown that intracortical transplantation with human iPSC-derived long-term neuroepithelial-like stem (hiPSC-lt-NES) cells led to better performance in cellgrafted animals as compared with vehicle-injected recipients, in the cylinder test at 4 and 7 weeks. In addition, transplanted cells expressed markers of neuroblasts and mature and GABAergic neurons on a background of reduced neuroinflammation and diminished neuronal death (Tatarishvili et al. 2014).

\section{Aging, cerebral ischemia, and genetic conversion-based therapies}

Although preclinical evidence for cell-based therapy offered encouraging results, the administration method plays a substantial role for the success of such treatments. For example, by intravenous delivery, only a fraction of the infused cells ends up in the ischemic hemisphere, and what is more, a large fraction of the remaining cells is lost due to the hostile hypoxic environment (Boltze et al. 2015). Furthermore, aging processes may generate a hostile environment for such treatments and may prevent the differentiation and integration of the infused cells in the existing neural circuits (Balseanu et al. 2014).

Therefore, the need for alternative therapies has emerged. Genetic conversion-based therapies offer a completely new approach when it comes to stroke therapy. This method of treatment targets cell fate reprogramming in the ischemic or injured area and may represent a breakthrough in the field of neurobiology (Fig. 1). While, as mentioned before, neurons are 


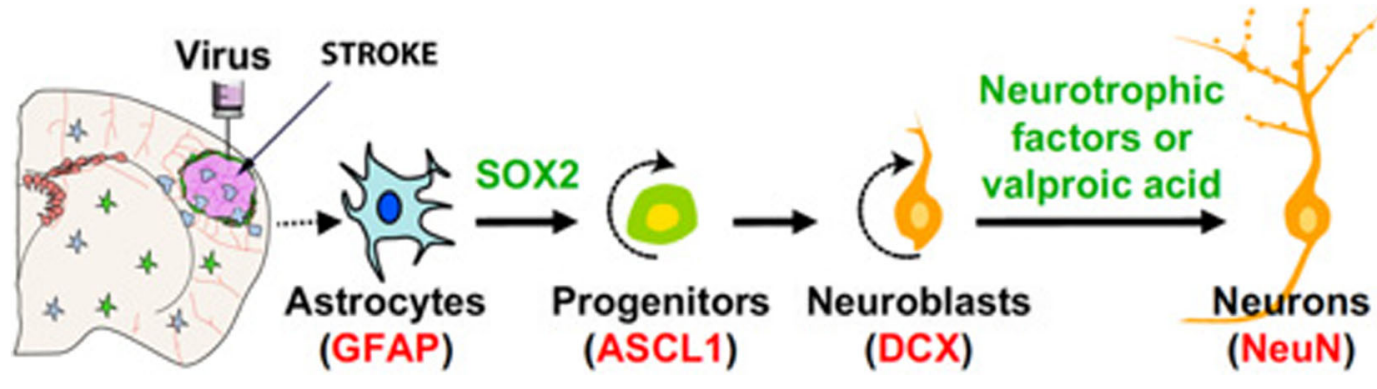

Fig. 1 In situ reprogramming of reactive astrocytes and NG2 cells into neuroblasts and mature neurons by retroviral expression of two transcription factors, Sox 2 and Ascl1 in the post stroke brain

frequently lost in the infarcted area, astrocytes become reactive and proliferative, disrupting the neurovascular cell balance in the lesioned area, especially in the aged brain. Astrocyte proliferation largely stops after 1 month of age (Ge et al. 2012; Tsai et al. 2012), but in response to neurodegeneration, adult astrocytes become reactive. This sequence of events also leads to a change in astrocyte morphology and proliferation status (Robel et al. 2011; Sofroniew and Vinters 2010). Most of these cellular processes are transitive in nature. They only last for several weeks to maximum 1 month after brain injury (Burda and Sofroniew 2014).

Another type of cells amenable to genetic conversion is neural stem cells (NSCs) located in the SVZ that respond to injury and migrate to the lesion area. Once there, NSCs differentiate into astrocytes (Benner et al. 2013; Faiz et al. 2015). It is precise that these SVZ derived cells that could be used for in vivo reprogramming (Benner et al. 2013).

Following cerebral ischemia, proliferating glia become reactive and build up a second barrier to regeneration, the glial scar. Although initially protective by confining the damaged area, in the long-term, the glial scar is acting as a physical and chemical barrier to neural regeneration by secretion of inflammatory cytokines such as TNF- $\alpha$ and interleukin-1 $\beta$ (IL-1 $\beta$ ) (Ferreira et al. 2015) and accumulation of neurite inhibitory factors such as chondroitin sulfate proteoglycans and lipocalin-2 (Koprivica et al. 2005; Silver and Miller 2004). Indeed, attenuating perilesional neuroinflammation using drugs or hypothermia can reduce neuronal death and stimulate angiogenesis (Buga et al. 2013; Fu et al. 2015; Sandu et al. 2016).

The aged rodent brain develops a fulminant inflammatory response to cerebral ischemia and an accelerated delimitation of the infarct zone by capillary-derived nestin-positive cells, further complicating the efficacy of any stroke therapy (Popa-Wagner et al. 2007). Therefore, it is also hoped that converting reactive astrocytes into neurons may also reduce microglia-mediated neuroinflammation and restore the neurovascular unit along with the blood-brain barrier. In this context, "melting" glial scars may address a crucial task for post stroke recovery (Silver 2016).

Astrocytes are the first nonneuronal cell type that has been proven to be capable of being reprogrammed in the adult mouse brain (Niu et al. 2013; Torper et al. 2013; Gao et al. 2016). What is more, recent studies showed that a number of different cell types such as NG2 glia and early postmitotic neurons within the nervous system are also reprogrammable in vivo.

Research carried out in the past decades identified a number of genes and transcription factors that play a critical role in the neuronal cell fate specification and maintenance. Thus, astrocytes and NG2 glia have been the target of studies that showed the successful conversion of reactive astrocytes and NG2 glia into glutamatergic neurons by retroviral expression of a single transcription factor, NeuroD1, in a model of stab wound brain injury (Guo et al. 2013).

Further conversions have been achieved by overexpressing Sox 2 in the adult brain and injured spinal cord (Niu et al. 2013). Sox 2 is a member of the Sox family of transcription factors. It plays important roles in a number of stages of mammalian development. A key role of Sox 2 is in the maintenance of embryonic stem cells (ESCs) and NSCs (Ferri et al. 2004).

Functional neurons can be generated in different brain regions using different combinations of genes for neural conversion with a focus on proneural genes. However, most of the reprogrammed neurons become interneurons. An improved approach to convert reactive glia into neurons using two transcription factors, Neurog2 and $\mathrm{Bcl}$, has been recently published (Gascón et al. 2016). It is 
important to mention that converted neurons were electrophysiologically active, and they were integrated into neural circuitry, a crucial requirement for post stroke recovery. Moreover, neurons generated by using three transcription factors, Ascl1, Lmx1a, and Nurr1, mature into fast-spiking, parvalbumin-containing interneurons and even integrate into existing brain circuitry (Pereira et al. 2017).

More recently, a different approach to astrocyte-toneurons conversion by targeting Pax 6 has been described by knocking down miR-365 to enhance PAX6-mediated neurogenesis. Conversely, increasing miR-365 expression in the ischemic brain inhibits astrocyte-to-neuron conversion (Mo et al. 2018). Other studies have shown that reactive astrocytes generated by cerebral ischemia have the properties of neural stem cells and can even transdifferentiate into neurons having the same morphological and functional characteristics as mature neurons (Shimada et al. 2012; Guo et al. 2013; Sirko et al. 2013; Magnusson et al. 2014; Duan et al. 2015).

This regenerative approach has been basically used in central nervous system lesions developing a glial scar. A different approach to "melting" the glia scar did use a lentivirus to silence the CTGF gene (also known as $\mathrm{CCN} 2$ or connective tissue growth factor) in order to prevent the formation of the glial scar tissue (Wang et al. 2018). The study, which has been carried out on female rats, concluded that lentivirus-mediated silencing of the CTGF gene could suppress the formation of glial scar tissue after spinal cord injury (Wang et al. 2018).

\section{Conclusions}

Currently, all methods for converting nonneuronal cells into neurons apply to the acute injured young brain. However, whether neuronal conversion and transdifferentiation can occur with the same efficacy in the aged brain is not known. Also, it is not known if this technology can be used long after the injury. Further problems such as the efficacy of cell conversion need to be addressed when it comes to improving behavioral recovery after cerebral ischemia in the aged subjects. For example, factors that have the ability to convert astrocytes to neurons in vitro (Berninger et al. 2007, Heinrich et al. 2010) fail to have the same effect in vivo (Grande et al. 2013). Successful conversion of astroglia to neurons following a brain lesion in young mice has been achieved using the following combinations of transcription factors: Ascll, Lmxla, and Nurr1 (https://doi.org/10.1016/j.stemcr.2017.07.023),
Pax6 (https://doi.org/10.1002/glia.23308), NeuroD1 (Guo et al. 2013), Ascl1/Ngn2 (Berninger et al. 2007), or Ngn2/Bcl2 (Gascón et al. 2016).

Therefore, other viral vectors such as adenoassociated viruses might be more efficient in promoting the conversion of reactive astrocytes to neurons after stroke in the aged brain.

However, this new approach of direct cellular reprogramming provides a path to create neurons from somatic cells in vitro (Vierbuchen et al. 2010). This may further lead to the ability to produce disease-specific and why not, patient-specific neurons which will open new horizons in the field of treatment for neurodegenerative diseases. Utilizing endogenously reprogrammed neurons for brain repair by in situ reprogramming of reactive astrocytes into functional neurons may completely change the way we cope with cerebral ischemia or neurodegeneration therapies. Therefore, further research generating cutting edge therapies in this area will definitely bring immense socioeconomic benefits to patients who suffer from neurodegenerative diseases.

Funding information This work was supported by the EU Framework Programme for Research and Innovation, Horizont 2020, project number 667302 to APW, and UEFISCDI, project numbers PN-III-P4-ID-PCE-2016-0340 to DH and PN-III-P2-2.1PED-2016-1013 and PN-III-P4-ID-PCE-2016-0215 to APW.

\section{Compliance with ethical standards}

Conflict of interest The authors declare that they have no conflict of interest.

\section{References}

Arvidsson A, Collin T, Kirik D, Kokaia Z, Lindvall O (2002) Neuronal replacement from endogenous precursors in the adult brain after stroke. Nat Med 8(9):963-970. https://doi. org/10.1038/nm747

Ay H, Koroshetz WJ, Vangel M, Benner T, Melinosky C, Zhu M et al (2005) Conversion of ischemic brain tissue into infarction increases with age. Stroke 36(12):2632-2636

Balseanu AT, Buga AM, Catalin B, Wagner DC, Boltze J et al (2014) Multimodal approaches for regenerative stroke therapies: combination of granulocyte colony-stimulating factor with bone marrow mesenchymal stem cells is not superior to G-CSF alone. Front Aging Neurosci 6:130. https://doi. org/10.3389/fnagi.2014.00130

Benner EJ, Luciano D, Jo R, Abdi K, Paez-Gonzalez P, Sheng H et al (2013) Protective astrogenesis from the SVZ niche after 
injury is controlled by Notch modulator Thbs4. Nature 497(7449):369-373. https://doi.org/10.1038/nature12069

Berninger B, Costa MR, Koch U, Schroeder T, Sutor B, Grothe B, Götz M (2007) Functional properties of neurons derived from in vitro reprogrammed postnatal astroglia. $J$ Neurosci 27(32): 8654-8664. https://doi.org/10.1523/JNEUROSCI.1615-07.2007

Boltze J, Arnold A, Walczak P, Jolkkonen J, Cui L, Wagner DC (2015) The dark side of the force - constraints and complications of cell therapies for stroke. Front Neurol 6:155. https://doi.org/10.3389/fneur.2015.00155

Buga AM, Di Napoli M, Popa-Wagner A (2013) Preclinical models of stroke in aged animals with or without comorbidities: role of neuroinflammation. Biogerontology 14(6):651662. https://doi.org/10.1007/s10522-013-9465-0

Burda JE, Sofroniew MV (2014) Reactive gliosis and the multicellular response to CNS damage and disease. Neuron 81(2): 229-248. https://doi.org/10.1016/j.neuron.2013.12.034

Darsalia V, Heldmann U, Lindvall O, Kokaia Z (2005) Strokeinduced neurogenesis in aged brain. Stroke 36(8):17901795. https://doi.org/10.1161/01.STR.0000173151.36031.be

Duan CL, Liu CW, Shen SW et al (2015) Striatal astrocytes transdifferentiate into functional mature neurons following ischemic brain injury. Glia 63(9):1660-1670. https://doi. org/10.1002/glia.22837

Faiz M, Sachewsky N, Gascón S, Bang KW, Morshead CM, Nagy A (2015) Adult neural stem cells from the subventricular zone give rise to reactive astrocytes in the cortex after stroke. Cell Stem Cell 17(5):624-634. https://doi.org/10.1016/j.stem.2015.08.002

Ferreira AC, Da Mesquita S, Sousa JC, Correia-Neves M, Sousa N, Palha JA, Marques F (2015) From the periphery to the brain: lipocalin-2, a friend or foe? Prog Neurobiol 131:120 136. https://doi.org/10.1016/j.pneurobio.2015.06.005

Ferri AL, Cavallaro M, Braida D, Di Cristofano A, Canta A, Vezzani $A$ et al (2004) Sox2 deficiency causes neurodegeneration and impaired neurogenesis in the adult mouse brain. Development 131(15):3805-3819. https://doi.org/10.1242/dev.01204

Fu Y, Liu Q, Anrather J, Shi FD (2015) Immune interventions in stroke. Nat Rev Neurol 11(9):524-535. https://doi. org/10.1038/nrneurol.2015.144

Gao X, Wang X, Xiong W, Chen J (2016) In vivo reprogramming reactive glia into iPSCs to produce new neurons in the cortex following traumatic brain injury. Sci Rep 6:22490. https://doi. org $/ 10.1038 /$ srep 22490

Gascón S, Murenu E, Masserdotti G, Ortega F, Russo GL, Petrik D et al (2016) Identification and successful negotiation of a metabolic checkpoint in direct neuronal reprogramming. Cell Stem Cell 18(3):396-409. https://doi.org/10.1016/j.stem.2015.12.003

Ge WP, Miyawaki A, Gage FH, Jan YN, Jan LY (2012) Local generation of glia is a major astrocyte source in postnatal cortex. Nature 484(7394):376-380. https://doi.org/10.1038/nature10959

Grande A, Sumiyoshi K, López-Juárez A et al (2013) Environmental impact on direct neuronal reprogramming in vivo in the adult brain. Nat Commun 4:2373. https://doi. org $/ 10.1038 /$ ncomms 3373

Guo Z, Zhang L, Wu Z, Chen Y, Wang F, Chen G (2013) In vivo direct reprogramming of reactive glial cells into functional neurons after brain injury and in an Alzheimer's disease model. Cell Stem Cell 14(2):188-202. https://doi. org/10.1016/j.stem.2013.12.001

Heinrich C, Blum R, Gascón S et al (2010) Directing astroglia from the cerebral cortex into subtype specific functional neurons. PLoS Biol 8(5):e1000373. https://doi.org/10.1371 /journal.pbio. 1000373

Hermann DM, Popa-Wagner A, Kleinschnitz C, Doeppner TR (2019) Animal models of ischemic stroke and their impact on drug discovery. Expert Opin Drug Discovery 14(3):315326. https://doi.org/10.1080/17460441.2019.1573984

Hou SW, Wang YQ, Xu M, Shen DH, Wang JJ, Huang F, Yu Z, Sun FY (2008) Functional integration of newly generated neurons into striatum after cerebral ischemia in the adult rat brain. Stroke 39(10):2837-2844. https://doi.org/10.1161 /STROKEAHA.107.510982

Jin KL, Wang XM, Xie L, Mao XO, Zhu W, Wang Y, ... Greenberg DA (2006) Evidence for stroke-induced neurogenesis in the human brain. Proc Natl Acad Sci U S A 103(35):1319813202. https://doi.org/10.1073/pnas.0603512103

Kempermann G, Song H, Gage FH (2015) Neurogenesis in the adult hippocampus. Cold Spring Harb Perspect Biol 7(9): a018812. https://doi.org/10.1101/cshperspect.a018812

Koprivica V, Cho KS, Park JB, Yiu G, Atwal J, Gore B, Kim JA, Lin E, Tessier-Lavigne M, Chen DF et al (2005) EGFR activation mediates inhibition of axon regeneration by myelin and chondroitin sulfate proteoglycans. Science 310(5745): 106-110. https://doi.org/10.1126/science.1115462

Kriegstein A, Alvarez-Buylla A (2009) The glial nature of embryonic and adult neural stem cells. Annu Rev Neurosci 32:149184. https://doi.org/10.1146/annurev.neuro.051508.135600

Magnusson JP, Göritz C, Tatarishvili J, Dias DO, Smith EM, Lindvall O, Kokaia Z, Frisén J (2014) A latent neurogenic program in astrocytes regulated by Notch signaling in the mouse. Science 346(6206):237-241. https://doi.org/10.1126 /science.346.6206.237

Ming GL, Song H (2011) Adult neurogenesis in the mammalian brain: significant answers and significant questions. Neuron 70(4):687702. https://doi.org/10.1016/j.neuron.2011.05.001

Mo JL, Liu Q, Kou ZW et al (2018) MicroRNA-365 modulates astrocyte conversion into neuron in adult rat brain after stroke by targeting Pax6. Glia 66(7):1346-1362. https://doi. org $/ 10.1002 /$ glia. 23308

Nadareishvili Z, Hallenbeck J (2003) Neuronal regeneration after stroke. N Engl J Med 348(23):2355-2356. https://doi. org/10.1056/NEJMcibr023192

Niu W, Zang T, Zou Y, Fang S, Smith DK, Bachoo R, Zhang CL (2013) In vivo reprogramming of astrocytes to neuroblasts in the adult brain. Nat Cell Biol 15(10):1164-1175. https://doi. org $/ 10.1038 / \mathrm{ncb} 2843$

Okano H, Yamanaka S (2014) iPS cell technologies: significance and applications to CNS regeneration and disease. Mol Brain 7:22. https://doi.org/10.1186/1756-6606-7-22

Pereira M, Birtele M, Shrigley S et al (2017) Direct reprogramming of resident NG2 glia into neurons with properties of fast-spiking parvalbumin-containing interneurons. Stem Cell Rep 9(3):742-751. https://doi.org/10.1016/j. stemcr.2017.07.023

Popa-Wagner A, Carmichael ST, Kokaia Z, Walker LC (2007) The response of the aged brain to stroke: too much, too soon? Curr Neurovasc Res 4:216-277. https://doi.org/10.2174 $/ 156720207781387213$

Popa-Wagner A, Buga A-M, Doeppner TR, Hermann DM (2014) Stem cell therapies in preclinical models of stroke associated with aging. Front Cell Neurosci 8:347. https://doi. org/10.3389/fncel.2014.00347 
Robel S, Berninger B, Götz M (2011) The stem cell potential of glia: lessons from reactive gliosis. Nat Rev Neurosci 12(2): 88-104. https://doi.org/10.1038/nrn2978

Roger VL, Go AS, Lloyd-Jones DM et al (2012) 2012. Heart disease and stroke statistics-2012 update: a report from the American Heart Association [published correction appears in Circulation. 2012 Jun 5;125(22):e1002]. Circulation 125(1): e2-e220. https://doi.org/10.1161/CIR.0b013e31823ac046

Sandu RE, Buga AM, Balseanu AT, Moldovan M, Popa-Wagner A (2016) Twenty four hours hypothermia has temporary efficacy in reducing brain infarction and inflammation in aged rats. Neurobiol Aging 38:127-140. https://doi. org/10.1016/j.neurobiolaging.2015.11.006

Shimada IS, LeComte MD, Granger JC, Quinlan NJ, Spees JL (2012) Self-renewal and differentiation of reactive astrocytederived neural stem/progenitor cells isolated from the cortical peri-infarct area after stroke. J Neurosci 32(23):7926-7940. https://doi.org/10.1523/JNEUROSCI.4303-11.2012

Silver J (2016) The glial scar is more than just astrocytes. Exp Neurol 286:147-149. https://doi.org/10.1016/j. expneurol.2016.06.018

Silver J, Miller JH (2004) Regeneration beyond the glial scar. Nat Rev Neurosci 5(2):146-156. https://doi.org/10.1038/nrn1326

Sirko S, Behrendt G, Johansson PA, Tripathi P, Costa M, Bek S et al (2013) Reactive glia in the injured brain acquire stem cell properties in response to sonic hedgehog. [corrected]. Cell Stem Cell 12(4):426-439. https://doi.org/10.1016/j.stem.2013.01.019

Sofroniew MV, Vinters HV (2010) Astrocytes: biology and pathology. Acta Neuropathol 119(1):7-35. https://doi. org/10.1007/s00401-009-0619-8

Stroke Therapy Academic Industry Roundtable (STAIR) (1999) Recommendations for standards regarding preclinical neuroprotective and restorative drug development. Stroke 30(12): 2752-2758 Review

Sun X, Zhang QW, Xu M, Guo JJ, Shen SW, Wang YQ, Sun FY (2012) New striatal neurons form projections to substantia nigra in adult rat brain after stroke. Neurobiol Dis 45(1):601609. https://doi.org/10.1016/j.nbd.2011.09.018
Tatarishvili J, Oki K, Buga AM, Popa-Wagner A, Brüstle O, Lindvall O, Kokaia Z (2014) Human induced pluripotent stem cells improve recovery in stroke-injured aged rats. Restor Neurol Neurosci 32(4):547-558. https://doi. org/10.3233/RNN-140404

Torper O, Pfisterer U, Wolf DA et al (2013) Generation of induced neurons via direct conversion in vivo. Proc Natl Acad Sci US A 110(17):7038-7043. https://doi.org/10.1073/pnas.1303829110

Tsai HH, Li H, Fuentealba LC, Molofsky AV, Taveira-Marques R, Zhuang $\mathrm{H}$ et al (2012) Regional astrocyte allocation regulates CNS synaptogenesis and repair. Science 337(6092):358-362. https://doi.org/10.1126/science.1222381

Vierbuchen T, Ostermeier A, Pang ZP, Kokubu Y, Südhof TC, Wernig M (2010) Direct conversion of fibroblasts to functional neurons by defined factors. Nature 463(7284):10351041. https://doi.org/10.1038/nature08797

Wang L, Chopp M, Zhang RL, Zhang L, Letourneau Y, Feng YF, Jiang A, Morris DC, Zhang ZG (2009) The Notch pathway mediates expansion of a progenitor pool and neuronal differentiation in adult neural progenitor cells after stroke. Neuroscience 158(4):1356-1363. https://doi.org/10.1016/j. neuroscience.2008.10.064

Wang Y, Kong QJ, Sun JC, Yang Y, Wang HB, Zhang Q, Shi JG (2018) Lentivirus-mediated silencing of the CTGF gene suppresses the formation of glial scar tissue in a rat model of spinal cord injury. Spine J 18(1):164-172. https://doi. org/10.1016/j.spinee.2017.01.004

Zhang QW, Deng XX, Sun X, Xu JX, Sun FY (2013) Exercise promotes axon regeneration of newborn striatonigral and corticonigral projection neurons in rats after ischemic stroke. PLoS One 8(11):e80139. https://doi.org/10.1371/journal. pone.0080139

Publisher's note Springer Nature remains neutral with regard to jurisdictional claims in published maps and institutional affiliations. 